\title{
Argumentação e pensamento crítico na educação científica: análise de estudos de casos e problematizações conceituais
}

\begin{abstract}
RESUMO
O objetivo geral deste artigo é apresentar uma breve revisão da literatura sobre um recorte específico do estado da arte em relação à presença do referencial teórico da argumentação e do pensamento crítico no ensino de ciências. Na primeira parte é realizada uma espécie de mapeamento prévio disponível em alguns artigos científicos de educação científica que se utilizem desta ferramenta. Nessa perspectiva, foram selecionados, através de busca no portal de periódicos da CAPES, alguns estudos de casos específicos para exposição e discussão de seus resultados a respeito dos usos da argumentação e seu potencial no aprendizado em ciências. Em um segundo momento, faz-se uma análise conceitual da importância e da contribuição, na educação científica e na formação de professores, que a utilização da argumentação e do pensamento crítico pode trazer vislumbrando uma aprendizagem fundamentada no entendimento crítico de temáticas científicas. Embora o escopo desta revisão seja bastante delimitado, nossa análise permite assumir que o uso da argumentação e pensamento crítico no ensino de ciências constitui-se em uma estratégia pedagógica potencial, que a literatura endossa ser possível utilizá-la tanto na educação básica como na formação de professores de Física e de Ciências, tornando a aprendizagem dos conteúdos mais significante e reflexiva.
\end{abstract}

PALAVRAS-CHAVE: Argumentação. Pensamento crítico. Educação científica. 


\section{INTRODUÇÃO}

A formação de professores de Física, e de Ciências, é uma linha de pesquisa importante na área da Pesquisa em Ensino, que tem conseguido avanços e aponta lacunas ainda existentes, por exemplo, nas relações (tensas) entre políticas públicas, academia e sistemas escolares (VILLANI, PACCA, FREITAS, 2009; PACCA, VILLANI, 2018), na produção de conhecimentos pedagógicos (GOUVEIA, 2001), no processo (lento) de uso de resultados de pesquisa educacional em sala de aula da educação básica (CARVALHO, GIL-PÉREZ, 2011; PENA, 2004), como o uso de processos investigativos e argumentativos, mais presente na literatura das duas últimas décadas (CARVALHO, SASSERON, 2018; VIEIRA, NASCIMENTO, 2007).

No presente trabalho pretende-se apresentar e na sequência discutir criticamente, de uma maneira bastante preliminar e sintética, o resultado de uma breve revisão de artigos recentes, publicadas tanto em revistas nacionais quanto internacionais, sobre o uso da lógica, da argumentação e do pensamento crítico como ferramentas didáticas para uma melhor e mais clara compreensão de determinados temas científicos, dentro do escopo do ensino de ciências da natureza. O objetivo é contribuir na promoção de uma aprendizagem mais eficiente e reflexiva no contexto do ensino por argumentação. A motivação teórica deste empreendimento é oriunda, basicamente, da forma bem sucedida com que o ensino de Filosofia se apropria e faz um uso didático da estratégia da lógica e da argumentação. A estratégia é útil para expor e discutir aspectos de teorias filosóficas, bem como de questões relevantes em relação à lógica enquanto ciência do raciocínio aplicada à resolução de problemas no nível da argumentação informal, utilizando-se basicamente da teoria do silogismo aristotélico e de teorias da argumentação contemporâneas, como, por exemplo, a de Stephen Toulmin.

A argumentação pode ser utilizada em vários contextos com fins didáticos, seja no Ensino de Filosofia e de Ciências Humanas, de uma forma geral, quanto na educação científica direcionada às Ciências da Natureza, que é o foco deste artigo. Este artigo está voltado para a análise de como a educação científica vem se apropriando, com resultados positivos, de ferramentas e recursos pedagógicos conforme realizado no ensino de Filosofia e também, em grau menor, de ciências humanas, especialmente das ciências sociais e jurídicas. A análise é feita com base nos resultados obtidos por um conjunto específico de artigos pesquisados na plataforma de busca do portal de periódicos da CAPES, e mostra a importância desta abordagem para uma aprendizagem com sentido para os estudantes e mais reflexiva, privilegiando o pensamento crítico (critical thinking, que tem dois níveis, o nível metodológico e o teórico-conceitual, como adiante se discute), tão carente e mesmo ausente, em grande parte, do ensino de ciências da natureza, mas bastante presente, como dito, em muitos setores do ensino de Filosofia e de Ciências Humanas. O grande foco da crítica que é realizada à educação científica, de modo geral, é de uma abordagem excessivamente expositiva, onde no mais das vezes se privilegia um modelo de aula em que o professor é que expõe o conteúdo de uma forma unilateral e que está focado, muitas vezes, na mera resolução de problemas matemáticos. Nessa perspectiva, o aluno assume um papel passivo no processo, resultando em uma aprendizagem memorística, ou seja, baseada na memorização de tais conteúdos e pela recursividade na resolução de exercícios padrão, não enfatizando nenhuma espécie de pensamento reflexivo e crítico. Trata-se de um ensino tradicional, possivelmente atrelado a uma formação de professores que centra a atenção nos conteúdos científicos (CARVALHO; GIL- 
PÉREZ, 2022, p. 21), e raramente proporciona ao aluno outra perspectiva de aprendizado que não esteja de alguma forma ancorada e embasada nesses métodos tradicionais.

O que se busca como metodologia de ensino mais eficaz na educação científica é não apenas uma alternativa a este modelo superado e arcaico na educação, mas uma proposta que vise à obtenção de cada vez mais aprendizagem de conceitos e tópicos científicos com sentido para os jovens, sendo que a argumentação e o pensamento crítico são candidatos a realizarem este objetivo. O que se expõe e se analisa neste trabalho está relacionado diretamente a este fim, ou seja, a apresentação e interpretação dos estudos de casos, além da tarefa de propor um diálogo e delimitar uma espécie de revisão de uma amostra de artigos localizados na literatura sobre o tema, amostra esta bastante limitada e encerrada no escopo a que tal pesquisa se propôs a investigar, não sendo meramente ilustrativa da questão do uso do argumento e do desenvolvimento do pensamento crítico em sala de aula, mas também procura identificar o quanto este uso, em termos de eficiência de resultados para o ensino de ciências, se mostrou pertinente para o estudo que se pretende aqui empreender.

\section{ASPECTOS METODOLÓGICOS}

Em relação à metodologia utilizada neste trabalho, o critério utilizado para a delimitação da busca da amostra foi o de incluir artigos publicados nos últimos cinco anos (2013-2018) em revistas e periódicos da área de ensino de ciências com o uso das palavras-chave "argumentação na educação científica", no portal da CAPES. Nessa plataforma foram encontrados inicialmente 186 registros (no caso, artigos revisados por pares) de trabalhos em língua portuguesa e espanhola; em um refinamento mais seletivo, foram selecionados 20 trabalhos mais relevantes dentre os 186 encontrados, onde os conteúdos dos resumos adequavam-se ao seguinte critério: presença do tema da argumentação no ensino de ciências. Destes 20 trabalhos selecionados, seis são expostos e analisados de uma forma mais cuidadosa neste artigo, sendo que um destes não foi publicado no período 20132018, mas sim em 2008, mas foi incluído porque é precisamente o que discute mais criticamente a argumentação na perspectiva de Toulmin no ensino de ciências. Em suma, trata-se de um estudo de caso que faz uma discussão mais conceitual e teórica sobre tal tópico, dentre outras questões importantes para a pesquisa. Isto, por si só, justifica sua inclusão nesse contexto, apesar do mesmo estar fora do período delimitado pela busca (revisão dos últimos cinco anos).

Uma vez explicitado e delineado, este procedimento metodológico de busca utilizado e os critérios estabelecidos para a seleção dos dados (isto é, dos artigos) como objeto da pesquisa presente, passamos agora, então, à exposição e análise dos estudos de casos contidos nos trabalhos selecionados.

\section{A PRESENÇA DE ARGUMENTAÇÃO E PENSAMENTO CRÍTICO NO ENSINO DE CIÊNCIAS: ANÁLISE DE ESTUDOS DE CASOS}

A fim de ilustrar as considerações iniciais acerca do horizonte teórico desta pesquisa, que se concentra essencialmente dentro do escopo explicitado no último parágrafo da seção anterior, começamos analisando o artigo de Alzate (2014), que 
faz uma discussão geral acerca do objeto de estudo da didática das ciências e sua relação com o campo da pedagogia. A discussão leva a estabelecer alguns limites e tensões entre a formação e o pensamento crítico em domínios específicos do conhecimento, como eixo central da didática das ciências, indo além dos objetivos convencionais centrados no ensino e aprendizagem das ciências. $O$ autor privilegia a tese do desenvolvimento do pensamento crítico de domínio específico, onde, em um segundo momento são apresentados resultados de investigação sobre a expressão do pensamento crítico em alunos, alunas e professores de séries iniciais da educação básica de 56 instituições públicas da cidade de Manizales, na Colômbia, no campo das ciências naturais. O estudo foi de natureza mista e as categorias investigadas foram resolução de problemas, metacognição e argumentação, elementos considerados como fundamentais para a formação e o desenvolvimento de critical thinking nos estudantes. Para a constituição dos dados da pesquisa, foram planejadas dez oficinas nas quais se apresentavam situaçõesproblema sobre diferentes temas de ciências, que envolveram 224 crianças e cinco professores. A investigação dividiu-se em três momentos, em que se realizaram a análise de cada uma das categorias, assim como a análise das relações entre elas. São apresentados os resultados independentes para cada uma das três categorias investigadas, assim como uma análise da relação entre elas em função da compreensão da expressão do pensamento crítico nas crianças investigadas; são descritas, ainda, as compreensões sobre as concepções dos professores acerca do pensamento crítico. Na linha de raciocínio que o autor propõe, a formação e o desenvolvimento do pensamento crítico, tanto nos estudantes como nos professores, é um dos propósitos mais básicos e fundamentais da educação, particularmente no caso específico da didática nas ciências, em que são identificados e apontados como elementos essenciais os processos de solução de problemas, argumentação e metacognição, conforme já referido.

A argumentação em ciências, nesta perspectiva, é condição necessária para uma compreensão profunda da atividade central do trabalho científico: tanto o estudante quanto o educador devem ter uma postura ativa frente ao processo de aprendizado, como, por exemplo, a questão da tomada de decisões que devem, em determinados momentos, ser realizadas para a resolução dos problemas propostos. Nas relações entre tais processos, o autor Alzate (2014) chama a atenção para o papel da metacognição dentro da argumentação científica, destacando sua importância para a construção de argumentos.

Por "metacognição" entende-se, no presente contexto, uma espécie de mecanismo epistemológico que visa descrever e explicar a aquisição do conhecimento e o controle que se tem sobre os próprios processos de pensamento, elementos estes determinantes para uma aprendizagem profunda e com significado, caracterizada pelo vínculo entre metacognição e argumentação, tanto no nível teórico quanto no experimental (ALONSO CRESPO, 1993; BAZIN, GIRED, 1999, BROWN, 1985), expressa o conhecimento que o sujeito tem quanto à sua cognição, uma tomada de consciência sobre o que sabe (ROSA, 2011).

Esta relação entre metacognição e argumentação é exposta e analisada com bastante detalhe em outro artigo que tem Alzate como coautor, intitulado "La argumentación metacognitiva em el aula de ciências" (SÁNCHEZ-CASTAÑO, CASTAÑO-MEJIA, ALZATE, 2015) em que ele e colaboradores relatam uma série de atividades realizadas com oito estudantes da educação básica, com idades entre 14 e 16 anos, que se voluntariaram para participar de experimentos que 
envolveram análises qualitativas em uma perspectiva do enfoque Ciência, Tecnologia e Sociedade (CTS), com três eixos norteadores, centrados respectivamente na relação sentir-pensar-atuar, na obtenção do conhecimento e do desenvolvimento da autonomia moral e intelectual e do pensamento crítico dos estudantes. Estes eixos são basilares na categoria da argumentação metacognitiva aplicada ao ensino de ciências.

Ao retomar o trabalho anterior do autor (ALZATE, 2014), destacamos que há dois momentos importantes no processo de argumentação na educação científica que ele procura descrever e utilizar em seu estudo, e que determinam, uma vez utilizados da forma adequada e apropriada, algum tipo de aprendizado, a saber: a redescrição das experiências de ensino nas situações apresentadas, em um primeiro momento, e em um segundo momento, redescrições livres destas experiências, utilizando as opiniões, crenças e analogias trazidas pelos alunos. A questão pertinente observada pelo autor neste ponto é que os estudantes retiram conclusões de experiências diretas, mas não respaldam justificadamente estas conclusões, e é justamente aqui que entra a importância do pensamento crítico na argumentação científica, pois tais conclusões devem, para terem efetivamente este estatuto, ser passíveis de revisão e reflexão crítica. Toulmin (2001) discute este aspecto em seu importante e seminal tratado sobre a argumentação, Os Usos do Argumento, ao qual voltaremos recorrentemente a fazer outras referências no decorrer deste trabalho, devido à importância que esta obra e este autor possuem para a temática.

No âmbito do pensamento crítico, há dois níveis a serem considerados: o nível metodológico e o nível teórico-conceitual. Não considerar este segundo nível é negligenciar o papel e a função do critical thinking como um elemento de construção teórico-conceitual que pode servir de referencial para o ensino de ciências, pois ressaltar apenas o aspecto da utilização do mesmo como uma ferramenta e um instrumento didático seria bastante limitador dentro deste universo de discurso e de atuação docente. Este aspecto é extremamente importante e relevante tanto a nível geral quanto no escopo da pesquisa realizada no presente artigo, e há que se chamar bastante a atenção para este ponto. Outro aspecto que chama a atenção no estudo de Alzate (2014) são as concepções dos professores acerca do uso da argumentação no ensino de ciências, assim como dos alunos entrevistados, para fornecer uma base de dados empíricos a partir dos quais alguns resultados de pesquisa foram inferidos. A conclusão é muito interessante e merece alguma reflexão: para boa parte desses educadores, a ausência significativa de pensamento crítico nos processos de aprendizagem não seria devido a uma deficiência na sua formação docente, mas sim nas formações discentes (dos alunos), sendo que a responsabilidade por tal carência teria mais relação com certa falta de interesse dos alunos, que nunca foram estimulados e incentivados para isso, do que dos professores enquanto alunos em seus cursos de licenciatura e em suas respectivas formações docentes. Este resultado específico parece revelar, em nossa interpretação do artigo em questão, algum preconceito nos juízos dos educadores acerca da questão da formação docente, e tal visão, por si só, já deveria ser razão suficiente para se tentar mudar tal postura, visando uma formação menos tradicional e baseada em currículos fechados e mais voltada para um perfil crítico e contestador.

Já em outra pesquisa, Plantin (2014) retoma a concepção de Toulmin sobre argumentação e a desenvolve no escopo da educação científica em um estudo 
apresentado em um Congresso Internacional realizado em Bogotá, Colômbia, em outubro de 2014, sobre formação de professores de ciências. O autor apresenta alguns exemplos que toma como base para a análise da argumentação científica no ensino, tendo sido um deles realizado em uma classe de Física sobre força e movimento. Os alunos suspendem uma pedra com um elástico e têm de analisar os conceitos físicos envolvidos no processo: em diversos momentos do experimento e nas repetições do mesmo, que os alunos realizavam mediante intervenções do professor. Diversas fases foram realizadas e algumas formas de argumentação foram testadas, tendo como intenção primordial a produção de alguma espécie de aprendizado derivado desta experiência. Um dos referenciais teóricos utilizados como base da intervenção, por exemplo, era a concepção de raciocínio revisável de Toulmin, assim como de outras concepções e teorias como, por exemplo, a de Perelman (1976) sobre o uso do recurso retórico na argumentação, e a de Hamblin (1970), sobre o caráter persuasivo e dialético que a argumentação desempenha no ensino de ciências, além da formação e da capacidade de desenvolvimento do espírito crítico proposto pelo critical thinking.

Embora Perelman defenda que a utilização da retórica como instrumento de persuasão na argumentação seja uma característica própria da Filosofia e das Ciências Humanas de um modo geral, Teixeira (2008) chama a atenção para o quanto este expediente é utilizado no ensino de ciências naturais, não apenas em relação ao discurso coerente retórico e persuasivo, mas também com respeito à argumentação científica, de modo geral, como instrumento legítimo de justificação para as conclusões das proposições da ciência que podem, e muitas vezes devem estruturar-se desta maneira, onde este instrumento de persuasão racional deve possuir alguma espécie de "força lógica" mais penetrante do que no âmbito da argumentação no senso comum e ordinário, que requer, neste contexto, menos rigor lógico e conceitual. Plantin (2014) destaca a importância, dentro desses propósitos, por exemplo, que os cafés científicos desempenham e podem e devem, também, influenciar no domínio da educação científica. Tais atividades, que se constituem em espaços não formais de aprendizagem, são extremamente importantes para a realização de debates orientados, onde se desenvolve o raciocínio crítico e a capacidade argumentativa. Ao explorar estas estratégias argumentativas como ferramentas didáticas para a educação em ciências, Plantin (2014) também investiga, na literatura, sobre o papel da lógica informal e da formação do pensamento crítico para a educação científica. Seu estudo adota, tanto no aspecto teórico quanto prático, como pano de fundo, a importância de alguns autores relevantes para tais fins, como, por exemplo, Kahane (1971), Blair e Johnson (1980) e Walton e Reed (2008), além da teoria da argumentação sob aspectos linguísticos de Anscombe e Ducrot (1983), estudos sobre as bases semânticas dos encadeamentos entre enunciados e a construção do objeto do discurso da lógica natural de Grieze $(1982,1990)$.

Tendo como objetivo, além de abordar a questão da argumentação na educação científica, discutir a função da Epistemologia de Lakatos (1993) e suas relações com a mudança conceitual no contexto do ensino, o estudo de Martins, Justi e Mendonça (2016) destaca a importância dada pelas autoras à construção de argumentos científicos para o ensino de ciências, avaliando a qualidade dos argumentos construídos pelos alunos como ferramenta de aprendizado e de comunicação de ideias, onde a capacidade crítica de reflexão é destacada no processo cognitivo de segunda ordem, no sentido de "como saber o que se sabe", e de transmitir o conhecimento científico adquirido reflexivamente através da 
argumentação e do pensamento crítico. A argumentação desempenha, segundo as autoras, um papel fundamental à autonomia intelectual e ao raciocínio do aprendiz e também na mudança conceitual, pois fomenta e desenvolve o caráter dialógico no processo de ensino-aprendizagem e favorece o interesse e o engajamento dos estudantes.

No escopo desse artigo, que utiliza a epistemologia lakatosiana como referencial teórico para o ensino de ciências, a argumentação é avaliada e analisada sob um viés sócio-científico, envolvendo 38 alunos de uma turma de segundo ano do ensino médio da rede pública de São Paulo. O tema das aulas da disciplina de Química eram interações intermoleculares, e os episódios foram gravados. Os estudantes não estavam acostumados com aulas de discussão de problemas em grupos, e as atividades consistiam em analisar o que acontecia com amostras de determinados elementos químicos, quando modificados, em relação às suas interações intermoleculares e iônicas, com a argumentação baseada nos principais conceitos da epistemologia de Lakatos (e.g., metodologia de programas de pesquisa, núcleo dos programas de pesquisa, cinturão protetor, heurística positiva e negativa).

A concepção de argumentação utilizada foi a de Deanna Kuhn (KUHN, 1991, 1993, 2014), do argumento baseado na tríade afirmativa, justificativa e evidência, que está centrada na ideia de compreender a ciência como argumento e de ensinála sob o viés da argumentação. Para Kuhn, nessa concepção tripartite, a afirmativa contida em um argumento é uma teoria, um ponto de vista, uma ideia ou uma opinião que se quer provar; a justificativa é a razão ou causa que dá suporte à afirmativa e a conecta com a evidência, com a observação, fato ou dado que oferece base ou sustentação a tal afirmativa.

Para ilustrar esse ponto, é conveniente trazer e mostrar como um caso da ciência pode ser estruturado em forma de argumento e como se dá essa relação. Usamos o caso da Astrofísica contemporânea: os astrônomos, algumas décadas atrás suspeitavam, mas não tinham evidência alguma, de que existissem planetas em outros sistemas planetários que não o nosso sistema solar. Tais cientistas lançaram essa hipótese, que seria a afirmativa na noção de argumentação de Dianne Kuhn, que precisaria ser provada de alguma forma para se constituir em conhecimento científico. As modernas técnicas de detecção desses corpos celestes vieram comprovar tal hipótese, a justificando, bem como as crenças dos astrofísicos nela. Assim elas se mostraram, com o tempo, verdadeiras. Uma diferença no brilho da estrela de determinado sistema, causada pelo trânsito do planeta ao passar na frente da mesma, foi tomada como evidência observacional de que a hipótese da existência de planetas extrassolares era confirmada, a corroborando pela observação e tornando-a um caso de conhecimento perante a comunidade científica. Ficava garantido que as crenças dos cientistas estivessem conectadas com esse fato de forma não acidental, isto é, esse tipo de evidência funcionou como apoio justificacional para as mesmas.

Retornando ao estudo de caso brevemente antes relatado no artigo de Martins, Justi e Mendonça (2016), de posse dos dados do mesmo as autoras concluíram que os "núcleos firmes dos programas de pesquisa lakatosianos" foram sempre os elementos que compuseram as afirmativas dos principais argumentos desenvolvidos pelos aprendizes e professores, assim como o cinturão protetor e as heurísticas positiva e negativa tiveram um papel importante também nesse processo. O papel que a noção de argumentação científica de Deanna Kuhn 
desempenha no ensino de ciências, em particular no contexto da temática das interações intermoleculares e também dos elementos centrais da epistemologia de Lakatos, foi fundamental na construção de um aprendizado significativo ancorado em desenvolvimento de pensamento crítico e da capacidade reflexiva pelos estudantes.

Uma constatação empírica que pôde evidenciar esse resultado foi a resistência dos aprendizes em refutarem, dentro da teoria química utilizada, as afirmativas do núcleo de pesquisa e do cinturão protetor da mesma sob um viés e uma perspectiva lakatosiana, implicando, com isso, uma construção do conhecimento científico fundamentado no processo da argumentação informal, onde o pensamento crítico e esta capacidade crítica são elementos essenciais para esta construção. $O$ artigo conclui também que a argumentação é um elemento que pode favorecer uma espécie de mudança conceitual nos estudantes, um resultado que estaria em alguma conformidade com este referencial teórico e também alinhado com a literatura (ARRUDA, VILLANI, 1994). O conflito de hipóteses contrárias nos debates orientados em sala de aula favoreceu a argumentação através do contraponto, sempre apresentando razões para argumentar de acordo com os cânones da argumentação informal de Kuhn, que desenvolve também no seu sistema cognitivo uma noção de que o professor/educador em ciências deva procurar superar uma visão ultrapassada, de senso comum, tanto da construção do conhecimento científico quanto de uma concepção canônica, de que se deve ensinar ciências a partir de uma perspectiva centrada na visão da ciência enquanto exploração; de que o conhecimento científico se dá pela interação do pesquisador com a natureza (a interação sujeito-objeto garantiria a verdade), através da observação e dos experimentos. Esta noção está superada e carrega, em si, uma visão equivocada de que esse processo funcionaria de forma análoga em relação à educação científica. Deanna Kuhn reconhece que este aspecto é parte essencial e é intrínseco da prática científica, mas que as atividades de natureza social, os aspectos sociocientíficos que devem ser considerados dentro dessas práticas, como a elaboração de explicações e teorias, e o debate em torno dessas ideias é tão essencial quanto os aspectos da exploração, que também é recorrente na prática científica. Sua concepção da argumentação como ferramenta essencial teórica e metodológica para a compreensão da ciência por parte dos estudantes, especialmente durante a educação básica, está ancorada nesses elementos. Tais atividades, se utilizadas adequadamente, promovem formas de pensar e raciocinar de maneira significativa e que se aproximariam mais da forma como os cientistas fazem/constroem ciência, isto é, sempre procurando revisar seus raciocínios e destacando o aspecto mutável, provisório e não definitivo tanto no processo de desenvolvimento do conhecimento científico como no de seu ensino.

Ao destacar os usos e a importância do argumento para a educação científica, o artigo de Nascimento e Vieira (2008) chama a atenção para o caráter não definitivo da argumentação, no sentido de raciocínio revisável que Stephen Toulmin e Deanna Kuhn defendem em detrimento da natureza permanente do silogismo lógico, por exemplo, em que a partir de um ponto de partida específico (premissas), chega-se a uma conclusão definitiva, característica dos raciocínios que não são passíveis de revisão. Estes argumentos não têm relevância para o aprendizado e perdem a sua função cognitivo-pedagógica, pois não podem ser reformulados. No início do artigo, a fim de introduzir o referencial, os autores destacam o assim chamado "padrão de Toulmin de argumentação", que é exposto e delineado no livro de Toulmin (2001), que destaca o caráter prescritivo da 
argumentação e se o mesmo é do tipo que pode e deve ser utilizado tanto em contextos do ensino de Filosofia quanto das Ciências Humanas, e também na educação científica de maneira geral.

Para Toulmin (2001), podem-se produzir argumentos para inúmeras finalidades, e nem sempre sua defesa pode ser dada por uma asserção formal direta; a principal característica e a função primordial destes (os argumentos) é o apoio que a conclusão recebe a partir das asserções e das proposições que compõem as suas premissas (segundo o esquema: premissa maior, premissa menor, conclusão), o que constitui propriamente o caráter justificatório dos argumentos, isto é, o seu uso justificatório primário, através da corroboração das asserções.

$\mathrm{Na}$ estrutura básica de um argumento, o autor destaca o que ele chama de dados, que são as proposições que compõem as premissas e que a partir de certo conjunto de garantias (o que confere propriamente a justificação) darão apoio, ou não, para a conclusão em questão. Tais garantias são chamadas por Toulmin de qualificadores modais. Confere-se certo grau de força justificatória das conclusões a partir das premissas dadas, ou de refutadores, se estes têm o papel de anular esta justificação, e, com isso, não conferir a garantia de que a conclusão se siga logicamente das premissas. É importante neste ponto destacar a diferença que existe entre o argumento, por si só, e a função que ele exerce na argumentação. Um ponto importante, também ressaltado por Toulmin (2001) é que o argumento tem a sua força justificatória por ele mesmo, dada a sua estruturação semântica e de como a conclusão está conectada com as premissas.

Contudo, o papel que o sujeito argumentador, aquele que utiliza o argumento para determinada finalidade (neste caso o agente do processo educacional científico, seja o aluno ou o professor), exerce se utilizando do mesmo como instrumento de persuasão e convencimento racional, é fator determinante para aquilo que Toulmin (2001) chamou de raciocínio revisável, conforme já mencionado anteriormente. Os argumentos dependem muito do contexto em que são utilizados e produzidos, e a função que os qualificadores modais exercem a fim de justificar as conclusões a partir das premissas, é elemento fundamental nesse processo em que o jogo argumentativo é desenvolvido.

No artigo de Nascimento e Vieira (2008), os autores analisam um estudo de caso que utiliza como referência o "padrão de Toulmin de argumentação", que eles denominam de uma "contribuição analítica" junto à formação inicial de professores, no curso de Licenciatura em Física, em que o objetivo era testar as intuições de estudantes que cursavam a disciplina de Prática de Ensino em Física e realizavam seu estágio docente. $O$ contexto era o de um experimento realizado em laboratório sobre o lançamento vertical de um corpo e a descrição do movimento por ele realizado na trajetória de subida e descida. O estudo foi de natureza etnográfica, realizado em uma universidade federal do sudeste brasileiro e envolveu aulas filmadas e também entrevistas. Como recurso para a identificação dos argumentos e de seus respectivos elementos constitutivos, foram realizadas transcrições dos episódios no formato de quadros proposicionais (NASCIMENTO, 1999). A partir do lançamento vertical para cima de um corpo, foi discutida a natureza do conhecimento científico e suas implicações para a aprendizagem através do expediente da coordenação de ideias, em que se deve chamar a atenção para as regras de utilização destas, reguladas por uma sintaxe e uma semântica 
próprias nem sempre óbvias e triviais da perspectiva de quem está realizando o experimento, teorizando e formando raciocínios para compreendê-lo.

Com esse expediente metodológico, os autores centraram-se na análise de conceitos fundamentais da Física (e.g., velocidade, aceleração e repouso). No caso da estrutura do primeiro argumento proposta pelo formador, que era um pesquisador experiente na área de didática em ensino de Física, foi considerado "dado" na premissa o fato do corpo (bola) estar em repouso no alto da sua trajetória, com velocidade nula; a "garantia de inferência explícita" (elemento que permite passar das premissas para a conclusão) é o que significa propriamente ter um instante com velocidade nula, o que caracteriza este conceito, e se não existir nenhum fator externo que recoloque o corpo em movimento, ele permanecerá parado no ponto mais alto da trajetória, é o que se poderia concluir desse argumento. Já no segundo argumento proposto pelo formador, em continuidade à descrição do experimento, toma-se como "dado" uma definição mais refinada do que significa o corpo estar em repouso, a saber, define-se o mesmo como um instante de tempo infinitesimal que decorre entre depois de ele parar, na subida da trajetória, e antes de cair e entrar em movimento novamente; a "garantia explícita" também é mais refinada, onde "parar" agora é entendido como sinônimo de permanecer um tempo parado (a noção de tempo aqui está explicitada, ao passo que não ocorria no argumento anterior), e a menos que o sentido de "parar" seja tomado como "ter velocidade nula em um instante do tempo" (o que seria o elemento da refutação potencial), pode-se, então, concluir que a bola não pára no ponto mais alto da trajetória: este argumento é contraditório com o primeiro, pois a conclusão é a negação da conclusão obtida no primeiro argumento, e isto é feito propositalmente pelo formador com o objetivo de propor uma reflexão crítica do caso para os licenciandos.

A partir destas considerações, os estudantes são desafiados a elaborar os seus argumentos a fim de oferecer suas explicações para o fenômeno. Ao formularem seus argumentos, dois licenciandos da turma em questão inferiram os mesmos resultados dos argumentos anteriores dos formadores, isto é, de que a bola não pára e de que ela pára. São resultados contraditórios, a partir de "dados" e "garantias" distintas: em um caso, um licenciando estipulou como dado que não há nenhum tempo em que a bola está na mesma posição, concluindo que a bola não pára; o outro licenciando concluiu, a partir do dado/premissa de que a bola tem velocidade zero, que ela pára, em que a garantia para tal inferência é implícita e condiciona o sentido de "parar" com um instante de velocidade nula. Em um momento posterior da análise, um desses licenciandos reestrutura o seu argumento baseado da noção de "permanecer um tempo", mesmo que infinitesimalmente pequeno, "na mesma posição", como garantia implícita da passagem do dado/premissa de que há uma contagem de tempo infinitesimalmente pequena para a conclusão de que a bola parou nesse tempo.

O ponto importante a se destacar neste estudo de caso é o quanto o papel das "garantias de inferência" pode desempenhar na passagem dos dados para a conclusão dos argumentos, e com isso se chegar às mesmas ou, então, a diferentes conclusões. Ao se aplicar o padrão analítico de análise argumentativa proposto por Toulmin (2001), é possível perceber que a função dos argumentos propostos pelo formador é a de colocar as bases da discussão para a turma, e, com isso, proceder a uma avaliação contínua da relação estabelecida entre os dados e as conclusões 
presentes nos argumentos desenvolvidos pelos licenciandos, se viabilizando a continuidade do processo argumentativo na análise do experimento em questão.

O estudo de caso aqui exposto e comentado, bem como outros semelhantes que mantêm esta mesma estrutura argumentativa, exemplifica o que se pretende com o desenvolvimento de pensamento crítico e reflexivo na argumentação científica quando se toma o "padrão de Toulmin" como referência conceitual. Ou seja, um movimento dialético e dialógico que carrega pelo menos dois elementos mediadores essenciais: as "garantias de inferência" e os "qualificadores modais', que visam à justificação da conclusão a partir das premissas e dos dados oferecidos. Para a teoria da argumentação de Toulmin, e como ficou demonstrado com os estudos de caso aqui expostos, o papel que as garantias oferecem no processo argumentativo, quer explícitas ou implícitas, é tão importante quanto o estabelecimento consistente dos dados e das conclusões, sob pena do argumento não ser qualificado como um bom argumento e não cumprir suas funções, que no caso envolvem processos cognitivos de aprendizagem com significado. A sintaxe da sua estruturação, a semântica dos termos envolvidos e a forma como estas estão conectadas na estrutura lógico-silogística são elementos essenciais para a sua finalidade primordial, que é a transmissão do conhecimento. No estudo de caso suprarreferido, segundo Nascimento e Vieira (2008) está bem ressaltado e explicitado este papel que as garantias desempenham na argumentação na seguinte passagem do seu artigo:

[...] as garantias enunciadas explicitamente pelo formador passaram a estruturar todos os argumentos subsequentes, sendo que tal estruturação operou através de restrições semânticas impostas pelas próprias garantias; no caso, as definições de repouso. Desta forma, isso nos remete a uma questão de dialogia orientada, pois o papel que as garantias exerceram internamente na estrutura de todos os argumentos esteve profundamente ligado ao plano semântico dos argumentos colocados inicialmente pelo formador. (NASCIMENTO; VIEIRA, 2008, p. 16).

Em relação aos qualificadores modais citados anteriormente, apesar de no estudo analisado não terem sido considerados explicitamente, sua função é, como processo de qualificação dos argumentos, a de estabelecer uma espécie de conexão entre os aspectos de avaliação internos e externos no processo argumentativo, em que tanto os elementos da constituição interna deste quanto o contexto discursivo são materializados modalmente como um qualificador associado à conclusão do argumento. Ou seja, é o que oferece, ao fim e ao cabo, as bases para a justificação do processo argumentativo, que pode, e mesmo deve, ter uma continuidade, se chegando sempre em uma conclusão provisória, passível de revisão por parte dos argumentadores e interlocutores, ou mesmo se chegando a uma espécie de consenso, ainda que com este mesmo aspecto de raciocínio revisável que Toulmin destaca em sua teoria como base fundamental para o processo argumentativo.

Embora no estudo de caso o "padrão de Toulmin de argumentação" aplicado à argumentação científica tenha se adequado, servindo como ferramenta metodológica para o ensino de Física, por exemplo, tal artifício nem sempre pode ser aplicado com essa finalidade, segundo os autores do estudo. Há casos onde há elementos contextuais e de assimetria entre os agentes interlocutores do processo argumentativo, em que os critérios de analiticidade não são totalmente condizentes com as práticas a serem analisadas (e.g., PLANTIN et al., 2008, que 
também versa sobre a validação da argumentação em sala de aula na formação inicial de professores de Física, mas em que os autores ressaltam que não utilizaram o padrão analítico de argumentação de Toulmin (2001) na condução da sua pesquisa).

Entretanto, tal ferramenta didática se mostrou bastante útil e eficaz para os casos expostos e analisados no estudo anterior (NASCIMENTO, VIEIRA, 2008), podendo também ter esta mesma funcionalidade e eficácia para casos semelhantes em que o padrão de argumentação de Toulmin (2001) se aplique bem e seja um instrumento relevante ao desenvolvimento de uma educação científica que produza aprendizagem cada vez mais com significado e substancial.

Também na linha da argumentação e do viés epistemológico como referencial teórico e metodológico para a educação científica, Berland (2016) e colaboradores analisam como a produção de práticas científicas pode se tornar relevante para o aprendizado. Em seu estudo, Berland e seus colegas defendem que a abordagem pedagógica centrada nas práticas deve ser projetada pelos professores com o objetivo de fazer com que os estudantes construam e apliquem o conhecimento, e não meramente os reproduzam através de uma educação formal centrada no conteúdo. Os aprendizes, nesta perspectiva, devem participar ativamente do seu processo de aprendizagem construindo argumentos, como, por exemplo, no padrão de Toulmin, oferecendo suporte para as proposições que querem defender através de razões e/ou evidências que garantam as conclusões a que chegarem.

Para Berland e colaboradores, é mais importante que o aluno saiba o que fazer do que propriamente saiba o conteúdo; defendem uma metodologia de ensino que dê primazia ao desenvolvimento de determinadas virtudes intelectuais, como autonomia, pensamento crítico e capacidade argumentativa, ao invés de o estudante apenas atingir o conhecimento. É mais importante para o seu aprendizado e sua formação como cidadão, saber como fazer, como se chegar nesse conhecimento do que propriamente obtê-lo pelo mero testemunho de quem o professa no ambiente escolar. Um argumento científico, nesta perspectiva e contexto, é parte de um conjunto de atividades desenvolvidas pelos alunos, com orientação dos professores, onde os atos de avaliação, justificação e revisão dos mesmos propiciam um aprendizado em que determinadas metas e objetivos devem ser alcançados, em detrimento de processos e rotinas de memorização que conduzam a uma espécie de aprendizagem mecânica. Uma abordagem baseada na prática para o ensino de ciências, segundo os autores, leva os alunos para além do desempenho rotineiro de ações ou processos científicos, fazendo com que desenvolvam uma construção intencional do conhecimento baseado na compreensão e no entendimento. Em seu artigo sobre práticas epistemológicas no ensino, Berland e seus colaboradores propõem na estrutura desta metodologia uma condição de engajamento e comprometimento por parte dos aprendizes, em que estes se tornem agentes ativos na construção do conhecimento científico, combinando práticas com as ideias que os mesmos trazem para os debates argumentativos na orientação dos seus trabalhos, conforme enfatiza, por exemplo Sandoval (2014), que também trata desta temática em seu trabalho. O objetivo geral desta construção coletiva é o de construir regras gerais para, através de modelos explicativos, descrever como o mundo natural funciona (conforme destacam, por exemplo, Lehrer e Schauble (2006), Osborne (2014), Passmore, Gouvea e Giere (2014)). 
É importante salientar que nesta estratégia de práticas epistemológicas é condição necessária, mas não suficiente, que os estudantes dominem a estrutura lógica de como construir um argumento e saibam como usá-lo em sala de aula e que o professor utilize com os mesmos esta ferramenta de ensino: é preciso ir para além destes usos, não correndo o risco de que as práticas acabem se reduzindo às rotinas de atividades referidas anteriormente. De fato, o desenvolvimento de habilidades cognitivas e virtudes intelectuais é um dos fatores mais importantes e preponderantes a serem levados em conta nesse processo. A concepção de "produto do conhecimento" ("knowledge product") é utilizada por Berland e colaboradores neste contexto das práticas epistêmicas no ensino de ciências, onde por tal "produto" compreende-se um modelo explicativo ou um argumento, por exemplo, que tenha a função de representar aquilo que se pretende ensinar no contexto de tais práticas. Por "ensinar" e "aprender" ciências se entende aquilo que Richard Duschl, por exemplo, quer dizer com esta terminologia, ao afirmar que se trata de "[...] um equilíbrio harmônico entre o aprendizado de conceitos científicos, aspectos sociais e práticas epistêmicas científicas" (DUSCHL, 2008, p. 268).

Nesta perspectiva, conceitos científicos seriam os significados semânticos de palavras aplicadas aos domínios da ciência dentro dos contextos específicos onde são aplicados, como, por exemplo, os conceitos de massa, campo e energia; os aspectos sociais são fatores externos à comunidade específica que influenciam as práticas científicas nas relações que se estabelecem entre ciência e sociedade, como, por exemplo, na perspectiva CTS (Ciência, Tecnologia e Sociedade) no ensino de ciências. Já as práticas epistêmicas, para Kelly, por exemplo, seriam “[...] os jeitos específicos pelos quais os membros de uma comunidade propõem, justificam, avaliam e legitimam enunciados de conhecimento dentro de um determinado contexto disciplinar [...]" (KELLY, 2008, p. 99). Isto corrobora, em larga medida, o que foi dito anteriormente, especialmente no que se refere à argumentação como ferramenta didática para a educação científica.

Seguindo esta linha de pesquisa dentro do ensino de ciências e este conjunto de metodologias centradas na argumentação aplicada à mesma, um estudo recente sobre a incorporação de práticas argumentativas sobre questões sociocientíficas na formação inicial de professores de Física (FIGUEIRA, NARDI, CORTELA, 2018) mostra-se muito relevante para uma discussão mais aprofundada sobre este tópico. No contexto deste estudo, realizado em uma disciplina de Didática da Ciência, obrigatória do sétimo semestre de um curso de Licenciatura em Física de uma universidade pública, foram realizadas três sessões argumentativas centradas em temas de cunho didático-pedagógico, de conceitos específicos de Física (em particular de Óptica) e de questões sociocientíficas. Os oito licenciandos participantes foram organizados em três grupos e receberam duas questões em papel impresso para leitura e discussão. Para tais atividades, os estudantes não tiveram instruções prévias e as mesmas foram realizadas visando obter subsídios para planejar outra atividade e também para analisar alguns comportamentos dos estudantes durante as situações argumentativas propostas.

Esta outra atividade foi realizada em um momento posterior, e consistiu em um debate na forma de uma audiência pública simulada sobre possibilidades futuras para o plano nuclear brasileiro. Os alunos foram reunidos em duplas e ficaram pré-estabelecido os papéis ficcionais dos mesmos nesta atividade, como, por exemplo, alguns se fazendo passar por membros da comissão do programa 
nuclear brasileiro, políticos que lidam com questões relativas à matriz energética no país e membros da Sociedade Brasileira de Física; incluiu também preparação intelectual de cada um para discorrer sobre os temas dos quais ficaram responsáveis. Os pesquisadores gravaram as audiências e realizaram anotações de campo para posterior análise do mesmo. De forma bastante resumida, os resultados mostram que a argumentação como metodologia de ensino se mostra bastante útil e eficaz, onde se faz necessária uma inversão entre os papéis do professor e do aluno no ambiente de sala de aula, conforme salientam JIMÉNEZ; ALEIXANDRE (2007), e também a diferença que existe entre o processo argumentativo e outras formas de orientações discursivas (VIEIRA; NASCIMENTO, 2013), elementos essenciais para que a prática argumentativa apareça naturalmente no ambiente escolar.

Na orientação discursiva argumentativa devem surgir divergências acerca de controvérsias científicas, tanto implicitamente quanto através de elementos externos, e tais divergências devem ser mediadas e sanadas por pontos de vistas justificados e com embasamento racional para a defesa destas opiniões. Cabe aos professores a tarefa de mediar e gerenciar tais divergências através do debate orientado e racional, onde através da discordância de opiniões bem fundamentadas lógica e epistemicamente, se produza conhecimento científico pelo viés das controvérsias sociocientíficas como, por exemplo, neste estudo de caso e em outros de semelhante natureza, ou em outros tipos de controvérsias dentro do contexto da educação científica. A formulação de juízos reflexivos éticomorais oriundos destas práticas epistêmicas aplicadas ao ensino de ciências gera autonomia intelectual e pensamento crítico, a partir da argumentação e remetem fortemente, mais uma vez, à presença do "padrão de argumentação de Toulmin" nestas práticas (VIEIRA, NASCIMENTO, 2013), o que parece ser um elemento bastante constante nas abordagens metodológicas levantadas sobre o uso da argumentação no ensino de ciências.

Na próxima seção, vamos problematizar um pouco mais esta questão, tanto em relação ao uso como também da importância do argumento para a educação científica.

\section{ALGUMAS PROBLEMATIZAÇÕES CONCEITUAIS ACERCA DOS USOS E DA IMPORTÂNCIA DA ARGUMENTAÇÃO NA EDUCAÇÃO CIENTÍFICA E CONSIDERAÇÕES FINAIS}

Ao elaborar as bases e os critérios conceituais para a sua teoria da argumentação em "Os usos do argumento", Toulmin (2001) estava preocupado, além da validade da estrutura lógica interna dos argumentos, com os seus diversos usos em diferentes contextos, onde racionalidades distintas estariam envolvidas e a discussão iria para além da pura validade formal que a lógica reputa aos argumentos dedutivos de maneira geral. Esta lógica é muito centrada em definições fechadas e um tanto dogmáticas em relação ao tipo de racionalidade que estaria inerente aos processos inferenciais realizados por diferentes agentes cognitivos, que não desempenham o mesmo raciocínio dadas as mesmas premissas e/ou dados e garantias para a obtenção de não necessariamente as mesmas conclusões. Apesar das reservas que um padrão analítico de argumentação como o de Toulmin pode sofrer se usado no ensino de ciências, os benefícios que tal estratégia didático-pedagógica pode trazer para a educação 
científica, no sentido de se produzir resultados mais significativos de aprendizagem, enfocando o pensamento crítico e a autonomia intelectual do estudante, é muito maior do que certas ressalvas e críticas pontuais que tal padrão pode apresentar. Basta, para isto, levar em conta a eficácia desta metodologia, tanto da perspectiva puramente teórica, quanto da sua aplicação em estudos de casos, como os que expusemos e discutimos neste trabalho. Peter Geach, em seu livro "Razão e Argumentação" (GEACH, 2012), por exemplo, também pode ser adotado como um referencial teórico útil à educação em ciências, pois assim como Toulmin dedica um capítulo inteiro de sua obra para tratar do uso da argumentação no contexto da lógica informal, de forma não técnica e acessível para não especialistas.

A lacuna nos currículos dos cursos das licenciaturas em ciências em termos de formação de pensamento crítico e reflexivo, assim como do uso do recurso do debate argumentativo em sala de aula é razoavelmente grande, e uma reforma substancial poderia e mesmo deveria ser pensada com este fim. Apesar de nos últimos trinta anos diferentes e inovadoras propostas para a reformulação do ensino de ciências terem sido oferecidas e mesmo normatizadas, como a abordagem CTS (Ciência, Tecnologia e Sociedade) e os seus aspectos sociocientíficos incorporados aos currículos e, com isso, a preparação para a cidadania ser um objetivo fundamental (SANTOS; MORTIMER, 2001), com elementos que possibilitem ao aprendiz uma tomada de decisão e um engajamento crítico nas discussões orientadas, ou mesmo o aprendizado baseado em TBL (Team Based Learning), por exemplo, onde o aluno é o maior responsável e protagonista pelo seu aprendizado, que está fundamentado na concepção do estudo e no desenvolvimento de atividades em grupos, com leitura e estudo de material prévio, onde a figura do professor é mais a de uma espécie de "orientador" ou "supervisor", o que evita, na medida do possível, a aula meramente expositiva, ainda há muito trabalho por ser realizado.

Uma mudança de mentalidade de como se produz e se transpõe o conhecimento científico precisa ser realizada de forma profunda e significativa, e não há outra forma de realizá-la senão engajando professores e futuros professores de Física e de Ciências nesta virada. É quase consenso, entre pesquisadores, que a alfabetização científica deve começar cedo na formação do aprendiz. O desenvolvimento do letramento e das capacidades argumentativas pode e deve ser um processo de construção coletiva e social, orquestrado pelo professor, onde indivíduos em cooperação tentam ajustar suas intenções e interpretações em torno de uma apresentação verbal que utilize critérios racionais capazes de guiar suas ações, onde através do instrumento da persuasão racional no debate, leve-se em conta o ponto de vista dos interlocutores (GEDDIS, 1991; SOLOMON, 1998), em que a tomada de decisão, tanto individual quanto em grupo, é de extrema importância a fim de obter-se um mínimo de aprendizado (RATCLIFFE, 1998).

Há que se fazer valer também o que está nas leis e nas políticas públicas educacionais, há quase duas décadas, como, por exemplo, o que está escrito sobre competências e habilidades que devem ser desenvolvidas durante o Ensino Médio, orientações que têm o mesmo norteamento do que estamos discutindo neste trabalho acerca da argumentação e do pensamento crítico na educação científica, especialmente o encontrado nas Diretrizes Curriculares Nacionais para a Educação Básica - DCNEB (BRASIL, 2013). Na parte das DCNEB que trata do Ensino Médio, 
particularmente na seção e no item sobre os pressupostos e fundamentos para um ensino médio onde trabalho, ciência, tecnologia e cultura fazem parte das dimensões que uma formação humana e social exige para o desenvolvimento da cidadania, e onde o processo da pesquisa no ensino tem uma função de princípio pedagógico norteador destas formações, é referido o conceito de "aprender a aprender" (BRASIL, 2013, p. 163), que se caracterizaria pelo discernimento adequado entre o que é mera informação e o que é conhecimento, especialmente frente aos novos conteúdos e tecnologias a que alunos, professores e toda a comunidade escolar estão expostos com o advento, cada vez maior, de novas ferramentas para o aprendizado. Isto pode ser percebido nas seguintes passagens, que destacam também outros aspectos essenciais a serem discutidos posteriormente:

O impacto das novas tecnologias sobre as escolas afeta tanto os meios a serem utilizados nas instituições educativas, quanto os elementos do processo educativo, tais como a valorização da ideia da instituição escolar como centro do conhecimento; a transformação das infraestruturas; a modificação dos papeis do professor e do aluno; a influência sobre os modelos de organização e gestão; o surgimento de novas figuras e instituições no contexto educativo; e a influência sobre metodologias, estratégias e instrumentos de avaliação. (Ibid., p. 163).

[...] apesar da importância que ganham esses novos mecanismos de aquisição de informações, é importante destacar que informação não pode ser confundida com conhecimento. $\mathrm{O}$ fato dessas novas tecnologias se aproximarem da escola, onde os alunos, às vezes, chegam com muitas informações, reforça o papel dos professores no tocante às formas de sistematização dos conteúdos e de estabelecimento de valores. (Idem).

Uma consequência imediata da sociedade de informação é que a sobrevivência nesse ambiente requer o aprendizado contínuo ao longo de toda a vida. Esse novo modo de ser requer que o aluno, para além de adquirir determinadas informações e desenvolver habilidades para realizar certas tarefas, deve aprender a aprender, para continuar aprendendo. Essas novas exigências requerem um novo comportamento dos professores que devem deixar de serem transmissores de conhecimentos para serem mediadores, facilitadores da aquisição de conhecimentos; devem estimular a realização de pesquisas, a produção de conhecimentos e o trabalho em grupo. Essa transformação necessária pode ser traduzida pela adoção da pesquisa como princípio pedagógico. (...). Ela instiga o estudante no sentido da curiosidade em direção ao mundo que o cerca, gera inquietude, possibilitando que o estudante possa ser protagonista na busca de informações e de saberes, quer sejam do senso comum, escolares ou científicos. Essa atitude de inquietação diante da realidade potencializada pela pesquisa, quando despertada no Ensino Médio, contribui para que o sujeito possa, individual e coletivamente, formular questões de investigação e buscar respostas em um processo autônomo de (re)construção de conhecimentos. (...) O relevante é o desenvolvimento da capacidade de pesquisa, para que os estudantes busquem e (re)construam conhecimentos. A pesquisa escolar, motivada e orientada pelos professores, implica na identificação de uma dúvida ou problema, na seleção de informações de fontes confiáveis, na interpretação e elaboração dessas informações e na organização e relato sobre o conhecimento adquirido. Muito além do conhecimento e da utilização de equipamentos e materiais, a prática de pesquisa propicia o desenvolvimento da atitude científica, o que significa 
contribuir, entre outros aspectos, para o desenvolvimento de condições de, ao longo da vida, interpretar, analisar, criticar, refletir, rejeitar ideias fechadas, aprender, buscar soluções e propor alternativas, potencializadas pela investigação e pela responsabilidade ética assumida diante das questões políticas, sociais, culturais e econômicas. (BRASIL, 2013, p. 163-164).

Nessas passagens das DCNEB é enfatizada a função da pesquisa como instrumento pedagógico. E como toda pesquisa tem caráter investigativo e exploratório, o que por si só já a caracteriza, isto tem relação direta com as discussões que fizemos anteriormente sobre a capacidade do entendimento e do pensamento crítico no processo de aprendizado na educação científica, podendose afirmar que tal prática está intimamente conectada com a argumentação e os usos do argumento no ensino de ciências, destacando também o aspecto de metaaprendizagem defendido por algumas correntes pedagógicas deste conceito de "aprender a aprender" no interior de um aprendizado contínuo e efetivo baseado nestas concepções. Contudo, existem educadores que são críticos desta posição, alegando e argumentando que ela não contribuiria para um aprendizado capaz de levar à autonomia intelectual. Todavia, o pensamento crítico e a capacidade argumentativa seriam justamente elementos que contraporiam esta concepção e trariam algum aprendizado mais efetivo e eficaz. Este tópico, contudo, é bastante complexo e exigiria muito mais elementos teóricos para discussão, e sua função no presente contexto é meramente ilustrativa e a nível comparativo. A construção de uma autonomia intelectual capaz de levar o sujeito a seguir aprendendo ao longo da vida pode conectar-se, dependendo do viés adotado, tanto com esta questão da meta-aprendizagem, quanto da argumentação crítica, que exige reflexão para que possa haver um entendimento mínimo envolvido, por exemplo, no discernimento, pelo agente educacional, entre o que é mera informação e o que é propriamente conhecimento, onde estas perspectivas não são necessariamente excludentes.

Toda esta discussão se faz cada vem mais pertinente e necessária em nossa sociedade diante da proliferação de falsas notícias (as assim chamadas Fake News), especialmente nos meios virtuais de comunicação e nas redes sociais de um modo geral. Ao exercer o pensamento crítico e a argumentação na educação científica, seja no ambiente escolar através de debates orientados e fóruns de discussão, ou na sociedade como boa divulgação do que seja propriamente o conhecimento científico e de como ele é construído, está-se contribuindo para a construção de um cidadão consciente, que desenvolva uma responsabilidade epistêmica adequada sobre o que ele vai justificadamente crer ou crer justificadamente (em conformidade com o objetivo epistêmico de que já falava o psicólogo cognitivo William James no Século XIX, que seria o de "crer em verdades e evitar crer em falsidades"), o que se constitui propriamente em uma virtude intelectual que fornecerá os elementos para ele bem discriminar racionalmente entre o conteúdo verdadeiro ou falso das suas crenças, no aspecto teórico, e também o "certo" do "errado" no nível prático das ações, como, por exemplo, já chamava a atenção René Descartes no seu "Discurso do Método", ao falar da capacidade do bom senso como sendo aquela que é a melhor distribuída entre o ser humano, no sentido de bem discernir entre o verdadeiro e o falso e o certo do errado.

Como se pode constatar nos extratos das DCNEB, conectado e integrado com as questões expostas anteriormente, a autonomia intelectual e moral do aprendiz, no sentido deste ser um agente crítico e transformador no processo da construção 
do conhecimento, e também um agente no tocante às tomadas de decisões referidas anteriormente, é um dos pontos centrais que esta formação crítica exige, onde um comprometimento com este tipo de ação é fundamental no processo do seu aprendizado ancorado no meta-aprendizado que requer reflexão crítica sobre os conteúdos e os processos todos em que tanto estudantes como professores e educadores têm o dever de desempenhar estas funções e estes papéis (isto é, de agentes críticos e transformadores). Embora não esteja explicitado o exercício da argumentação como instrumento didático visando a uma formação de senso crítico no aluno, seja na educação básica de maneira geral, particularmente no ensino de ciências, mais especificamente nos conteúdos expressos nas DCNEB, ela está presente pelo menos tácita e implicitamente nas questões abordadas e discutidas, o que mostra a importância e relevância de tal instrumento e fazer valer, na prática, tal empreendimento é um dever de todo o professor que prime pela qualidade e excelência no ensino.

Ao se considerar o processo da alfabetização científica como um todo para o exercício da cidadania, tanto esses fatores arrolados quanto certos elementos inelimináveis da comunicabilidade entre os interlocutores na argumentação para haver a presença de um discurso mínimo, coerente e inteligível, como se exige que tenha que ocorrer na educação científica de maneira geral, não se pode considerar nessa perspectiva apenas o indivíduo isoladamente, no caso o aprendiz apenas, e sim o ambiente da sala de aula e os aspectos contextuais e socioculturais que permeiam o entendimento de como o conhecimento científico avança e é obtido (como no caso, por exemplo, das perspectivas CTS e TBL citadas e comentadas anteriormente). Neste aspecto, autores como Bakhtin (1992) e Lotman (1988), da escola russa linguística, por exemplo, em seus estudos aplicados ao campo da educação e aos processos cognitivos de ensino e aprendizagem, são de extrema relevância para o desenvolvimento do aprendizado no sujeito, pois condicionam o significado das proposições veiculadas no processo de ensino com o caráter público e contextual e das condições sociais que, através destes elementos, realizam a cognição - o aspecto linguístico é condição necessária nesse processo todo, por isso o apelo a uma alfabetização e a um letramento científicos consistentes, no sentido de ser um conjunto de práticas às quais uma pessoa lança mão para interagir com o mundo e os conhecimentos dele (SASSERON; MACHADO, 2017). Tal empreendimento só será bem realizado e efetivado com a prática do discurso argumentativo bem orientado, do raciocínio revisável de Toulmin, por exemplo, que sempre irá requerer novos usos de razões para justificar e oferecer garantias às suas conclusões a partir dos dados que estão disponíveis para tanto, além de outras teorias da argumentação que possam ser aplicadas no contexto da educação científica.

Os usos e vantagens da argumentação para o ensino de ciências, tanto da perspectiva do referencial teórico importado da lógica informal, das teorias da racionalidade e da análise de argumentos, quanto da mesma como ferramenta metodológica a serviço de uma aprendizagem consistente e eficiente centrada na fixação e significação de conceitos a partir do discurso crítico, reflexivo e dialógico, obtido e aperfeiçoado através das práticas recorrentes da realização de inferências cujos objetivos da cogência, da transmissão e da justificação das verdades dos dados e das premissas para a conclusão, são os objetivos epistêmicos, cognitivos e pedagógicos essenciais a serem perseguidos e alcançados. São altamente importantes e relevantes, onde os avanços conquistados são visíveis e incontestáveis, e sua defesa está plenamente justificada tanto pela exemplificação 
da eficácia de aprendizagem nos estudos de caso aqui expostos e analisados, como pelos próprios elementos e conceitos que caracterizam as teorias da argumentação, de modo geral, e os diversos usos que o argumento pode e deve fornecer para uma educação científica significativa, responsável e que atinja os seus objetivos mais básicos e essenciais, que é fomentar e promover o aprendizado como um fim em si mesmo. 


\title{
ARGUMENTATION AND CRITICAL THINKING IN SCIENTIFIC EDUCATION: ANALYSIS OF CASE STUDIES AND CONCEPTUAL PROBLEMATIZATIONS
}

\begin{abstract}
The general objective of this article is to present a brief review of the literature on a specific outline of the state of the art in relation to the presence of the theoretical framework of argumentation and critical thinking in science education. In the first part, a kind of prior mapping is carried out, available in some scientific articles of scientific education that use this tool. In this perspective, some specific case studies were selected by searching the CAPES journals portal for exposure and discussion of their results regarding the uses of argumentation and its potential for learning in science. In a second step, a conceptual analysis of the importance and contribution is made, in scientific education and in the training of teachers, which the use of argumentation and critical thinking can bring to glimpse a learning based on the critical understanding of scientific themes. Although the scope of this review is quite limited, our analysis allows us to assume that the use of argumentation and critical thinking in science education constitutes a potential pedagogical strategy, that the literature endorses the possibility of using it both in basic education and in training of physics and science teachers, making learning content more meaningful and reflective.
\end{abstract}

KEYWORDS: Argumentation. Critical thinking. Scientific education. 


\section{REFERÊNCIAS}

ALONSO CRESPO, Francisco. Metacognición y aprendizaje: influencia de los enfoques, conocimientos metacognitivos y práctica estratégica sobre el rendimiento académico, en alumnos de ESO. 1993. Tese (Doutorado) Departamento de Psicología Evolutiva y de la Educación, Universidad Complutense de Madrid, Madrid, 1993.

ALZATE, O. E. T. Pensamiento crítico domínio específico em la didáctica de las ciências. TED, n. 36, p. 25-45, 2014.

ANSCOMBRE, J. C.; DUCROT O. L'argumentation dans la langue. Bruxelles, Mardaga, 1983.

ARRUDA, S. M.; VILLANI, A. Mudança conceitual no ensino de ciências. Caderno Catarinense de Ensino de Física (atual Caderno Brasileiro de Ensino de Física), v.11, n2: p. 88-99, 1994.

BAKHTIN, M. M. Estética da criação verbal. São Paulo, Martins Fontes, 1992.

BAZIN, Anne; GIRED, Robert. A metacognição, um apoio ao sucesso dos alunos da escola primária. In: GRANGEAT, Michel (Coord.). A metacognição, um apoio ao trabalho dos alunos. Tradução de Teresa Maria Estrela. Porto, Portugal: Porto Editora, 1999. p. 61-91.

BERLAND, L. K., SCHWARZ, C. V., KRIST, C., KENYON, L., LO, A.S., REISER, B.J. Epistemologies in Practice: making scientific practices meaningful for students. Journal of Research in Science Teaching, Vol. 53, Num. 7, p. 1082-1112, 2016.

BLAIR, J. A. y JOHNSON, R. H. Informal logic: The first international symposium. Inverness, Edgepress, 1980.

BRASIL. Diretrizes Curriculares Nacionais para a Educação Básica (DCNEB). Ministério da Educação, Conselho Nacional de Educação. Organização: Jaqueline Moll, 2013.

BROWN, A. Metacognition: the development of selective attention strategies for learning from text. In: SPIRO, Rand J.; BRUCE, Bertram C.; BREWER, William (Eds.). Theorical models and processes of reading. International reading association: Deleware, 1985. p. 285-301. 
CARVALHO, A. M. P., SASSERON, L. H. Ensino e aprendizagem de Física no Ensino Médio e a formação de professores. Estudos Avançados, vol. 32, n. 94. São Paulo, 2018. https://doi.org/10.1590/s0103-40142018.3294.0004

DUSCHL, R. A. Science education in three-part harmony: Balancing conceptual, epistemic, and social learning goals. Review of Research in Education, 32(1), p. 268-291, 2008.

FIGUEIRA, M.J.S., NARDI, R., CORTELA, B.S.C. Um estudo sobre a incorporação de práticas argumentativas sobre questões sociocientíficas na formação inicial de professores de Física (A study on the implementation of argumentation practices about socioscientific issues in Physics teachers initial education). XVII Encontro de Pesquisa em Ensino de Física, 2018.

GEACH, P. Razão e Argumentação. Editora Penso, 2012.

GEDDIS, A. N. Improving the quality of science classroom discourse on controversial issues. Science Education, v. 75, n. 2, p. 169-183, 1991.

GOUVEIA, M. S. F. Pesquisa e prática pedagógica na formação do professor: Como entendê-la? Proposições, v. 12, n. 1, p. 27-46, 2001.

GRIZE, J. B. De la lógica a la argumentación, 1982.

HAMBLIN, Ch. L. Falacies. London, Methuen, 1970.

JIMÉNEZ-ALEIXANDRE, M. P. Designing argumentation learning environments. In: ERDURAN. S.; JIMÉNEZ-ALEIXANDRE, M. P. Argumentation in Science Education: Perspectives from Classroom-Based Research. Holanda: Springer Publishers, $p$. 91-116, 2007.

KAHANE, H. Logic and Contemporary Rhetoric: The Use of Reason in Everyday Life. Belmont, Wadsworth, 1971.

KELLY, G. J. Inquiry, activity and epistemic practice. In: DUSCHL, R.; GRANDY, R. (Eds.) Teaching Science Inquiry: Recommendations for Research and Implementation. Holanda: Rotterdam Sense Publishers, p. 99-117, 2008.

KRESS, G.; JEWITT, C.; OGBORN, J.; TSATSARELIS, C. Multimodal teaching and learning: the rhetorics of the science classroom. London: Continuum, 2001. 
KUHN, D. Science as argument: implications for teaching and learning scientific thinking. Science Education, v. 77, n. 3, p. 319-337, 1993.

KUHN, D. The Skills of Argument. New York: Cambridge University, 1991.

KUHN, D., HEMBERGER, L., \& KHAIT, V. Argue with Me - Argument as a Path to Developing Students' Thinking and Writing. Bronxville, N.Y: Wessex, 2014.

LAKATOS, I. La metodología de los programas de investigación científica. Madrid: Alianza, 1993.

LEHRER, R., \& SCHAUBLE, L. Scientific thinking and science literacy: Supporting development in learning in contexts. In W. Damon, R. M. Lerner, K. A. Renninger, \& I. E. Sigel (Eds.), Handbook of child psychology, 6th ed. (Vol. 4, p. 153-196). Hoboken, NJ: JohnWiley and Sons, 2006.

LOTMAN, Y. M. Text within a text. Soviet Psychology, v. 26, n. 3, p. 32-51, 1988.

MARTINS, M., JUSTI, R., MENDONÇA, P.C. O papel da argumentação na mudança conceitual e suas relações com a Epistemologia de Lakatos. Educacíon Química 27, p. 3-14, 2016.

NASCIMENTO, S., VIEIRA, R. Contribuições e limites do padrão de argumento de Toulmin aplicado em situações argumentativas de sala de aula de ciências.

Revista Brasileira de Pesquisa em Educação em Ciências, Vol. 8, Num. 2, p. 1-20, 2008.

NASCIMENTO, S. S.; PLANTIN, C.; VIEIRA, R. D. A validação de argumentos em sala de aula: um exemplo a partir da formação inicial de professores de física.

Investigações em ensino de Ciências, v. 13, n. 2, IFURGS, Porto Alegre, 2008.

Disponível em

http://www.if.ufrgs.br/ienci/artigos/Artigo ID181/v13 n2 a2008.pdf

OSBORNE, J. F. Teaching scientific practices: Meeting the challenge of change. Journal of Science Teacher Education, 25(2), p. 177-196, 2014.

PACCA, J. L. A., VILLANI, A. A formação continuada do professor de Física. Estudos Avançados, vol. 32, n. 94, 2018. https://doi.org/10.1590/s0103$\underline{40142018.3294 .0005}$. 
International handbook of research in history, philosophy and science teaching (p. 1171-1202). Netherlands: Springer, 2014.

PENA, F. L. A. Por que, apesar do grande avanço da pesquisa acadêmica sobre ensino de física no Brasil, ainda há pouca aplicação dos resultados em sala de aula? Revista Brasileira de Ensino de Física, São Paulo, v. 26, n. 4, p. 293-295, 2004.

PERELMAN,, Ch., Olbrechts-Tyteca L. ([1958]/1976). Traité de l'argumentation. La nouvelle rhétorique. Préface de E. Bréhier. Paris, puf. 3e éd. 1976, Editions de I'Université de Bruxelles.

PLANTIN, C. Lengua, argumentación y aprendizages escolares. TED, Num. 36, p. 95-114, Jul-Dec. 2014.

L'argumentation: Histoire, théories et perspectives. Paris: Presses Universitaires de France. Collètion Qus sais-je?, 2005.

RATCLIFFE, M. Discussing socio-scientific issues in science lessons - pupils' actions and the teacher's role. School Science Review, v. 79, n. 288, p. 55-59, 1998.

Rosa, C. T. W. A metacognição e as atividades experimentais no Ensino de Física. Tese (Doutorado). Universidade Federal de Santa Catarina, Centro de Ciências da Educação. Programa de Pós-Graduação em Educação Científica e Tecnológica. Florianópolis, 2011.

SÁNCHEZ-CASTAÑO, J.; CASTAÑO-MEJIA, O. ; ALZATE, T. O. La argumentacíon metacognitiva en el aula de ciências. Revista Latinoamericana de Ciencias Sociales, Niñez y Juventud, Vol.13(2), p.1153-1168, Jul-Dec. 2015.

SANDOVAL, W. A. Science education's need for a theory of epistemological development. Science Education, 98(3), 383-387. doi: 10.1002/sce.21107, 2014.

SANTOS, W. L. P.; MORTIMER, E,F.; \& SCOTT, P. H. A argumentação em discussões sócio-científicas: reflexões a partir de um estudo de caso. Revista Brasileira de Pesquisa em Educação em Ciências, I(1), p. 140-152, 2001.

SASSERON, L. H.; MACHADO, V. F. Alfabetização científica na prática: inovando a forma de ensinar Física. São Paulo: Livraria da Física, 2017. 
TEIXEIRA MARTINS, F. Argumentação nas aulas de ciências para as séries iniciais. En Sousa do Nascimento, S. y Plantin Chr. (orgs.), (2009). Argumentação e ensino de ciências. Editora crv, Curitiba, 2008.

TOULMIN, S. Os usos do argumento. Trad. R. Guarany, Martins Fontes, São Paulo, 2001. (Tradução do original inglês The uses of argument, Cambridge: Cambridge University Press, 1958).

VIEIRA, R. D., NASCIMENTO, S. S. A argumentação no discurso de um professor e seus estudantes sobre um tópico de mecânica newtoniana. Cad. Bras. Ens. Fís., v. 24, n. 2: p. 174-193, 2007.

VIEIRA, R. D., NASCIMENTO, S. S. Argumentação no ensino de ciências: tendências, práticas e metodologia de análise. $1^{\mathfrak{a}}$ ed. Curitiba: Editora Appris, $113 p, 2013$.

VILLANI, A.; PACCA, J. L. A.; FREITAS, D. Science teacher education in Brazil: 19502000. Science \& Education, v. 18, n. 1, p.125-148, 2009.

WALTON, D., REED, C. y Macagno, F. Argumentation schemes. Cambridge, Cambridge University Press, 2008.

Recebido: 11 fev. 2019

Aprovado: 14 mai. 2020

DOI: $10.3895 /$ rbect.v13n2.9563

Como citar: GUIMARÃES, R. R.; MASSONI, N. T. Argumentação e pensamento crítico na educação

científica: análise de estudos de casos e problematizações conceituais. Revista Brasileira de Ensino de

Ciência e Tecnologia, Ponta Grossa, v.13, n. 2, p. 320-344, mai./ago. 2020. Disponível em:

<https://periodicos.utfpr.edu.br/rbect/article/view/9563>. Acesso em: XXX

Correspondência: Ricardo Rangel Guimarães - rirangel@gmail.com

Direito autoral: Este artigo está licenciado sob os termos da Licença Creative Commons-Atribuição 4.0 Internacional. 